\title{
Analysis of the Effect of Using Camshaft Racing on Power and Torque in Motorcycle
}

\author{
Hasan Maksum ${ }^{1}$, Wawan Purwanto ${ }^{2}$, Miky Andes Putra ${ }^{3}$, Hanapi Hasan ${ }^{4}$ \\ \{hasan_maksum@yahoo.co.id',wawan5527@ft.unp.ac.id²,mikyandesputra99@gmail.com³ \\ hanapi_hasan@unimed.ac.id $\left.{ }^{4}\right\}$ \\ Department of Automotive, Faculty of Engineering, Universitas Negeri Padang, Indonesia ${ }^{1,2,3}$, \\ Department of Mechanical Engineering, Faculty of Engineering, Universitas Negeri Medan, Indonesia ${ }^{4}$
}

\begin{abstract}
This study examines the power and torque generated by the use of camshaft racing on a motorcyclewith $125 \mathrm{cc}$ rotary engine 4500,6000 and $7500 \mathrm{rpm}$. Data was analyzed by means of directly observing experimental results then summed and determine the results of the research that has been done in the form of graphs and tables. In this test of dynamometer used tool to determine power and torque. The results of this study indicate that increased use camshaft torsional rotation racing at $4500 \mathrm{rpm} 1.21 \mathrm{Nm}$ $(18.42 \%)$, whereas at $6000 \mathrm{rpm}$ rotation increased by $1.61 \mathrm{Nm}(22.61 \%)$ and $7500 \mathrm{rpm}$ rotation torque is increased $1.7 \mathrm{Nm}(30.20 \%)$. Then the power increase in use of $0.82 \mathrm{~kW}$ racing camshaft $(26.37 \%)$ in the round of $4500 \mathrm{rpm}, 6000 \mathrm{rpm}$ while the rotation increased by $0.99 \mathrm{~kW}(20.10 \%)$ and $7500 \mathrm{rpm}$ rotation power increased by 1.46 $(33.87 \%)$.
\end{abstract}

Keywords: Camshaft Racing, Power, Torque, Motorcycle.

\section{Introduction}

The internal combustion engine (ICE) has been optimized for more than half a century, although the approach and purpose of optimization have changed over the years in response to changes in the environment in which the engine is used [1]. Policy changes, improved technology, revised fuel and reduced vehicle and engine sizes are indicated as possible ways to improve vehicle fuel economy, which in turn reduces pollutant emissions [2]. In the last three decades, advanced technologies such as Direct Injection, turbocharging, and Variable Camshaft Timing (VCT) have contributed significantly to the evolution of engine design [3]. The combination of this technology, together with the reduction in engine size, has simultaneously had a positive effect on fuel consumption and emissions, as well as on driving pleasure [4].

The mechanics took many ways to produce high-performance motorcycles, which is to make modifications to the engine. Modifications made by making important components on the motor, especially on the cylinder head. This is because bicycle engine power is generated by the combustion process at the cylinder head

There are various ways to make modifications to the cylinder head. One of them is by porting the inlet and exhaust, redesigning the combustion chamber, enlarging the ventilation holes in the carburetor, making changes to the inlet and exhaust valve, and much more. 
This is done with the aim of getting as much fuel and air supply as possible into the cylinder head. In other words, it aims to obtain Volumetric efficiency as much as possible is expected to produce optimal power. To get maximum efficiency of volumetric to produce the most optimal power it can be done by the camshaft modifications or replacements.

Camshaft is an important part of car engines and other internal combustion engines. Quality and work efficiency have a direct influence on automotive quality and the development of the entire automotive industry [5]. The role of the camshaft is to determine the valve opening time, set the valve duration of the opening duration, determines the length of the Valve inlet and Exhaust Valve duration and the main components of the valve-train mechanism. Properly opening and closing the valve or valve on the cylinder head will increase engine power [6]. Rotary camshaft engine vibrations cause increased wear, unpleasant noise, and improper movement which will reduce their performance and reliability $[7,8]$.

Modifying or replacing a standard camshaft with camshaft racing aims to obtain higher performance. That is why research needs to be carried out to what extent the difference in the influence of the use of standard camshafts and camshaft racing on motorcycle, which in turn can be obtained differences in power and torque. Therefore, researchers are interested in examining and diagnosing "The Effects of Using Camshaft Racing on Motorbikes' Power and Torque".

\section{Theoritical Review}

\section{Camshaft}

Camshaft is an eccentric projection on a rotating shaft that is used to regulate the opening and closing of valves with various mechanical intermediaries such as a timming chain or timming belt [9]. In a camshaft design, both intake lobes and exhaust lobes, they must have their respective peaks. The peak of the intake lobe is called the intake lobe centerline and the peak of the exhaust lobe is also called the exhaust lobe centerline. The distance between the two lobes is called a lobe separation; because it is measured in degrees, it is called a lobe separation angle. Lobe separation angle (LSA) is also called the distance in camshaft rotation between the intake lobe centerline and the exhaust lobe centerline.
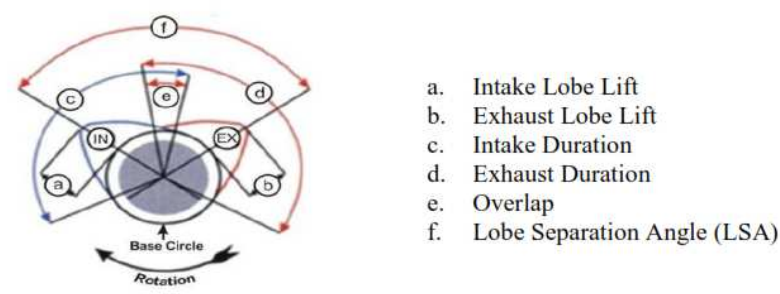

Fig 1. Camshaft Parts

\section{Camshaft Racing}

In order to meet maximum motor performance, it can be done through an analysis of modifying the camshaft. This is done in principle to get a faster and longer duration of the inlet valve opening. While the exhaust valve opening is made late and closes faster. Modifications are made by changing the angle formed between the inlet cam and the exhaust cam, which are not the same for each engine. The assumption of the camshaft degree can be determined by looking first at each motor brand and model because it has a different character, 
here it is needed special expertise and high accuracy to evaluate and refine motor work in order to overhaul work performance or motor power performance in order to produce maximum power. Among them by changing the cam degree angle, duration, lift and overlap to determine the optimal valve work. To increase engine speed is to modify the camshaft/cam/noken as [9].

Camshaft racing is a camshaft whose main function is better than the standard camshaft, For example: (1) A valve that is pressed deeper serves to increase the fuel that goes into and (2) The valve is open longer so that there is more time which is available for the fuel to go into the cylinder. The following can be illustrated a diagram of the opening/closing time of the valve on a standard camshaft and a 4 stroke $125 \mathrm{cc}$ motorcycle racing camshaft:

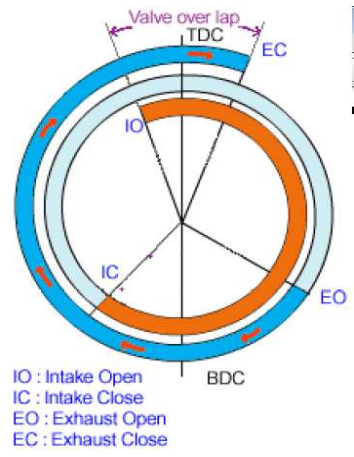

Fig 2. Standard camshaft valve diagram

A standard camshaft with duration of $260^{\circ}$, that is, the valve goes into, will open at the point $2^{\circ}$ before TMA, and will close at the point $25^{\circ}$ after TMB and the exhaust valve will open at point $34^{\circ}$ before TMB and will close at the point $0^{\circ}$ after TMA. The camshaft has a $6.5 \mathrm{~mm}$ camshaft lobe lift for suction valves and $6 \mathrm{~mm}$ for exhaust valves.

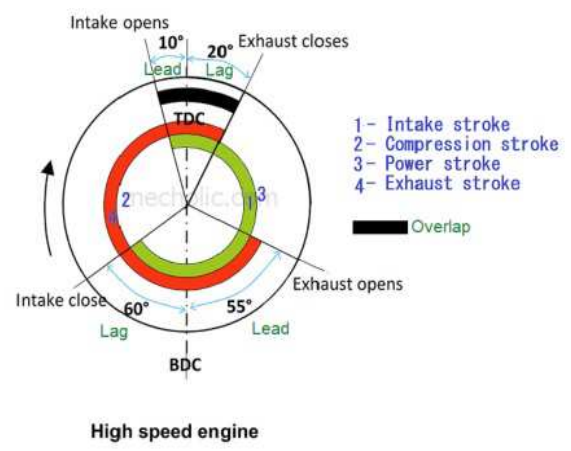

Fig 3. Camshaft racing valve diagram

Camshaft racing with the duration of $270^{\circ}$, the inlet valve will open at a point $10^{\circ}$ before TMA and will close at a point $60^{\circ}$ after TMB and the exhaust valve will open at point $55^{\circ}$ before TMB and will close at a point $20^{\circ}$ after TMA. This camshaft has an $8 \mathrm{~mm}$ camshaft lift lobe for suction valves and $8 \mathrm{~mm}$ for exhaust valves. 


\section{The Effects of Using Camshaft Racing on Power and Torque}

The use of camshaft racing will affect at least a mixture of fuel and air that enters or goes into the combustion chamber. The actual volume of air entering/going into the cylinder can be expressed in a ratio between the volume of air entering and the volume of piston steps from the upper dead point to the lower dead point. This figure/number is hereinafter referred to as "Volumetric Efficiency". If the number/figure of volumetric efficiencies is greater, more air will enter/go into the cylinder and the flow will be smoother.

The efficiency of the intake of a mixture of air and fuel (filling efficiency) is, the ratio between the volume of the mixture of fuel and air at ambient pressure and temperature. Increasing the volume of air/fuel entering/going into the cylinder means that there are more explosions will be used to produce power $[9,11]$.

\section{Research Method}

In this research model, there is an experimental group and a control group with a pattern in the table below.

Table 1. Experiment Group

\begin{tabular}{|c|c|c|l|}
\hline Group & Treatment & test result & Note \\
\hline $\mathrm{R}$ & - & $0_{1}$ & $\begin{array}{l}\text { motorcycle using } \\
\text { camshaft standard }\end{array}$ \\
\hline $\mathrm{R}$ & $\mathrm{X}$ & $0_{2}$ & $\begin{array}{l}\text { motorcycle using } \\
\text { camshaft racing }\end{array}$ \\
\hline
\end{tabular}

Description:

$\mathrm{R} \quad$ : Experimental and control group

$\mathrm{X} \quad$ : Treatment using camshaft racing

$\mathrm{O}_{1} \quad$ : Effect without treatment

$\mathrm{O}_{2} \quad$ : The effect after using camshaft racing

\section{Object of Research}

The object of research is the target or object that is the subject of discussion in research. The object of research in this study is a four-stroke motorcycle unit. In this case, the data to be taken is the power and torque of the motorcycle. Specifications of the motorcycle used:

Table 2. Specifications of motorcycle type $125 \mathrm{cc}$

\begin{tabular}{ll}
\hline \multicolumn{1}{c}{ Item } & \multicolumn{1}{c}{ Specification } \\
\hline Engine Type & 4 steps SOHC 2-Air cooling valve \\
Number of cylinder & 1 \\
Displacement & $124,8 \mathrm{cc}$ \\
Bore x stroke & $52,4 \times 57,9 \mathrm{~mm}$ \\
Compression ratio & $9,0: 1$ \\
Maximum Torque & $10.1 \mathrm{Nm} / 4000 \mathrm{rpm}$ \\
Maximum power & $6,94 \mathrm{~kW} / 7500 \mathrm{rpm}$ \\
\hline
\end{tabular}




\section{Research procedure}

This research was conducted in several stages;

\section{Preparation phase}

First (a) The preparation stage of the machines and tools needed in the research process; (b) Before the test is carried out, the motorcycle is reconditioned according to the manufacturer's standards without any changes or modifications; (c) Then start the motor at its idle speed for 5 minutes so that the motor reaches its working temperature, which is $\pm 80^{\circ} \mathrm{C}$; (d) After reaching the working temperature, the engine is turned off and the motorcycle is positioned on the dynamometer; (e) Install dynotest safety equipment; (f) Turn on the vehicle cooling blower; (g) Start the vehicle engine, then calibrate the engine compression ratio on the dynamometer.

\subsubsection{Power and torque Testing Phase}

Firtst (a) Turn the gas handle slowly up to $2000 \mathrm{rpm}$, then press the start/stop dynamometer button, the gas handle is then rotated until the engine reaches the maximum rotation, after the engine reaches the maximum rotation then the gas handle is released slowly until the idle turns and pushes the start/stop dynamometer button; (b) Print the results of power and torque tests; (c) Steps "a" and "b" are repeated 3 times, to get the best results; (d) Printing test results in the form of power and torque at an engine speed of 4500, 6000 and $7500 \mathrm{rpm}$.

\subsubsection{Data Analysis Stages}

Researchers conduct data analysis to reveal increased power and torque by using camshaft racing and standard camshafts at 4500, 6000 and 7500 rpm engine speeds.

\section{Results and Discussion}

\subsection{Research Finding (Result)}

Table 3. Torque testing data $(\mathrm{Nm})$ using standard camshaft and camshaft racing.

\begin{tabular}{|c|c|c|c|c|c|c|c|c}
\multirow{4}{*}{ RPM } & \multicolumn{9}{|c}{ Torgue } \\
\cline { 2 - 10 } & \multicolumn{4}{|c}{ Standard } & \multicolumn{5}{c}{ Racing } \\
\cline { 2 - 10 } & $\mathbf{1}$ & $\mathbf{2}$ & $\mathbf{3}$ & Mean & $\mathbf{1}$ & $\mathbf{2}$ & $\mathbf{3}$ & Mean \\
\hline $\mathbf{4 5 0 0}$ & 8,12 & 4,99 & 6,61 & 6,57 & 8,36 & 8,67 & $\mathbf{7 , 7 8}$ & 8,27 \\
\hline $\mathbf{6 0 0 0}$ & 7,71 & 6,58 & 7,07 & 7,12 & 9,34 & 9,11 & 7,75 & 8,73 \\
\hline $\mathbf{7 5 0 0}$ & 5,38 & 6,32 & $\mathbf{5 , 1 9}$ & $\mathbf{5 , 6 3}$ & 8,04 & 7,59 & 6,36 & $\mathbf{7 , 3 3}$ \\
\hline
\end{tabular}

Table 4. Power test data $(\mathrm{kW})$ using standard camshaft and camshaft racing.

\begin{tabular}{|c|c|c|c|c|c|c|c|c|}
\hline \multirow{3}{*}{ RPM } & \multicolumn{9}{|c|}{ Power (kW) } \\
\cline { 2 - 9 } & \multicolumn{4}{|c|}{ Standard } & \multicolumn{5}{c|}{ Racing } \\
\cline { 2 - 9 } & \multicolumn{4}{|c|}{ Testing } & \multicolumn{5}{c|}{ Testing } \\
\cline { 2 - 9 } & $\mathbf{1}$ & $\mathbf{2}$ & $\mathbf{3}$ & Mean & $\mathbf{1}$ & $\mathbf{2}$ & $\mathbf{3}$ & Mean \\
\hline $\mathbf{4 5 0 0}$ & $\mathbf{3 , 8 6}$ & 2,36 & 3,11 & 3,11 & 3,95 & 4,09 & 3,74 & 3,93 \\
\hline $\mathbf{6 0 0 0}$ & 4,85 & 4,15 & 4,44 & 4,48 & 5,88 & 5,73 & 4,80 & 5,47 \\
\hline $\mathbf{7 5 0 0}$ & 4,23 & 4,61 & 4,08 & 4,31 & 6,33 & 5,96 & 5,02 & 5,77 \\
\hline
\end{tabular}




\subsection{Research Chart/Graph}

Based on the results of the tests which have been done, the mean/average data from three tests can be converted into graphs as follows.

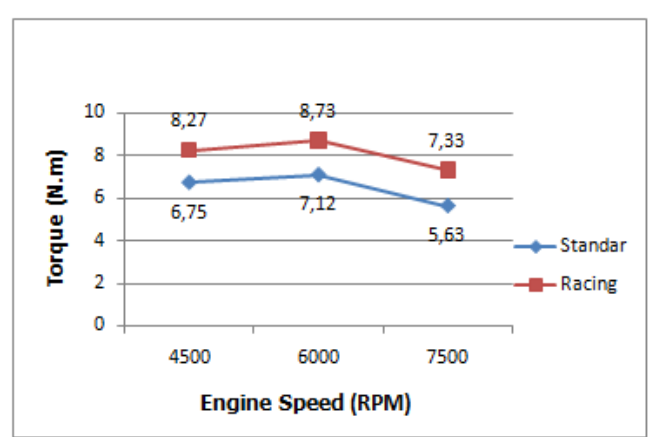

Fig 4. Comparison graph of torque testing on standard and racing camshafts

On the graph, it can be seen that the use of camshaft racing affects the torque produced by the $125 \mathrm{cc}$ motorcycle engine. At $4500 \mathrm{rpm}$ using a standard camshaft has a torque of 6.75 $\mathrm{Nm}$ and an increase in the use of camshaft racing $8.27 \mathrm{Nm}$, then at $6000 \mathrm{rpm}$ using a standard camshaft produces torque of $7.12 \mathrm{Nm}$ and an increase of $8.73 \mathrm{Nm}$ on the use of camshaft racing and at 7500 rotation the data shows that on a standard camshaft produces torque of 5.63 $\mathrm{Nm}$ while on camshaft racing the torque data increases to $7.33 \mathrm{Nm}$.

In the $4500 \mathrm{rpm}$ rotation test using standard camshaft produces $3.11 \mathrm{~kW}$ power and an increase in the use of $3.93 \mathrm{~kW}$ camshaft racing, then at $6000 \mathrm{rpm}$ rotation using standard camshaft produces $4.48 \mathrm{~kW}$ power and an increase of $5,47 \mathrm{~kW}$ in the use of camshaft racing and in the round of 7500 the data shows that using a standard camshaft produces power of $4.31 \mathrm{~kW}$ while in camshaft racing the power data increases to $5.77 \mathrm{~kW}$.

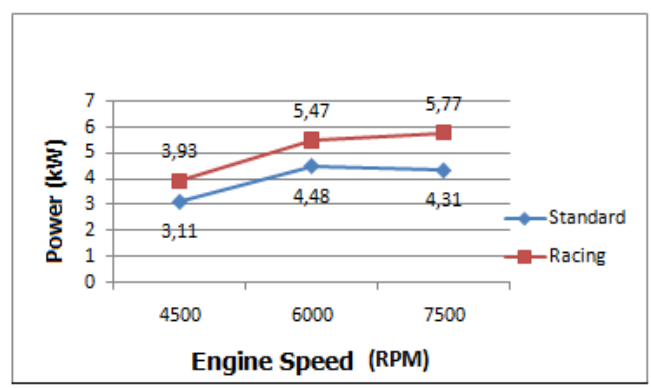

Fig 5. Comparison of power testing charts on a standard and racing camshaft

In the process of implementing the t-test results of this study, the thiting price will be searched. The results of the $t_{\text {hiting }}$ will be compared with the $t_{\text {table }}$ to see the significance level. The value of the $t_{\text {table }}$ used is at a significant level of $5 \%$ which is equal to 2776 . The power and torque analysis that is carried out consists of two groups: standard conditions with the use of camshaft racing. This analysis is described in the following table

Table 5. Data Analysis of Torque Testing on $125 \mathrm{cc}$ Motorcycle.

\begin{tabular}{|c|c|c|c|c|c|c|c|c|c|}
\hline \multicolumn{10}{|c|}{ Comparative Analysis of Torque on a Standard Camshaft with Camshaft Racing } \\
\hline RPMI & $\underset{\text { arenge }}{X}$ & $\underset{\text { arenage }}{\mathrm{Y}}$ & $\mathrm{n}_{\mathrm{X}}$ & & SI & Sv & tes & & \\
\hline 4500 & 6,57 & 7,78 & 3 & & 19 & 0 , & $-2,506$ & 2.776 & \\
\hline 6000 & 2 & 8,73 & $j$ & & 0,1429 & & 3 & 2.1 & \\
\hline 7000 & 5,63 & 7,33 & 3 & $j$ & 0,2479 & 1,0067 & $-2,195$ & 2.7 & \\
\hline
\end{tabular}


The results of the analysis show significant and insignificant in the use of camshaft racing towards the torque produced by the engine. The use of camshaft racing results is not significant to the torque at 4500 and 7500-rpm engine speed with a $\mathrm{t}_{\text {count }}$ of $-2.506 \mathrm{Nm}$ which is smaller than the $t_{\text {table }} 2,776$ at 4500 rotation and at $7500-r p m$ with a $t_{\text {count's }}$ value of -2.195 less than $t_{\text {table }} 2,776$, whereas at 6000 rounds, the results were significant with a $t_{\text {count }}$ of 3.560 $\mathrm{Nm}$ which was greater than the $\mathrm{t}_{\text {table }} 2,776$. That is, the null hypothesis (Ho) against torque is accepted and the alternative hypothesis $(\mathrm{Ha})$ is rejected because there are insignificant results of the analysis of torque testing data.

Table 6. Data Analysis of Power Testing Results on 125 cc Motorcycle.

\begin{tabular}{|c|c|c|c|c|c|c|c|c|c|}
\hline \multicolumn{10}{|c|}{ Comparative Analysis of Power on a Standard Camshaft with Camshaft Racing } \\
\hline RPM & ${ }_{\substack{\text { axerage }\\
}}$ & $\underset{\text { avenge }}{\mathrm{Y}}$ & $\mathrm{n}_{\mathrm{X}}$ & $\mathrm{n}_{\mathrm{Y}}$ & Sx & Sy & $T$ tes & Ttabel & Significance \\
\hline 4500 & 3,11 & 3,93 & 3 & 3 & 0,06 & 0,06 & 3,700 & 2.776 & Significant \\
\hline 6000 & 4,48 & 5,47 & 3 & 3 & 0,15 & 0,06 & 3,240 & 2.776 & Significant \\
\hline 7500 & 4,31 & 5,77 & 3 & 3 & 0,06 & 0,06 & 6,590 & 2.776 & Significant \\
\hline
\end{tabular}

Based on data analysis of above it is obtained $t_{\text {count }}$ which is then compared with $t_{\text {table. }}$ The use of camshaft racing results significantly in powers at 4500, 6000 and 7500-rpm engine speeds with a $t_{\text {count }}$ of $3,700 \mathrm{~kW}$ which is greater than the $t_{\text {table }} 2,776$ at 4500 turns, at $6000-\mathrm{rpm}$ at a tune of $3,240 \mathrm{~kW}$ greater than the $t_{\text {table }} 2,776$. Then at 7500 rounds, the $t_{\text {count }}$ of $6.590 \mathrm{~kW}$ is also greater than the $t_{\text {table }} 2.776$. The value of the $t_{\text {table }}$ used is at a significant level of $5 \%$. That is, the null hypothesis (Ho) towards/against the power is rejected and the alternative hypothesis (Ha) is accepted.

\subsection{Discussion}

The data on the results of power and torque testing on a $125 \mathrm{cc}$ motorcycle using camshaft racing using dyno test can be seen in tables 3 and 4 as well as the graphs in figures 3 and 5 .

The data and hypotheses put forward are in accordance with the theory, to meet maximum motor performance, an analysis can be made to modify the camshaft [9]. This is done in principle to get a faster and longer duration of the inlet valve opening. While the exhaust valve opening is made late and closes faster. Modifications are made by changing the angle formed between the inlet cam and the exhaust cam, which are not the same for each engine. The assumption of the camshaft degree can be determined by looking first at each motor brand and model because it has a different character, here it is needed special expertise and high accuracy to evaluate and refine motor work in order to modify work performance or motor power performance in order to produce maximum power. Among them by changing the cam degree angle, duration, lift and overlap to determine the optimal valve work. To increase engine speed is to modify the camshaft/cam/noken as."

The increased torque and power due to the use of camshaft racing which is inseparable from the theory every change in valve lift settings will affect the entire valve and cylinder. The 
shape and size of the cam largely determines the point of movement, speed of opening and closing the valve and the amount of valve lift from the seat [9].

Based on the results of testing the power and torque using dynotest, the test shows that the increase in power and torque occurs at a minimum rotation up to a certain rotation which is the peak torque and power, then at higher engine speed, torque and power will decrease. Both torque and power are function as engine speed. At low speed, torque increases as engine speed increases, as engine speed increases the torque reaches a maximum and then decreases [10]. Torque decreases because the engine is unable to ingest a full charge of air at higher speeds. Indicated power increases with speed, while power increases to a maximum and then decreases at higher speeds. This is because friction losses increase with speed and become the dominant factor at very high speeds. For many automobile engines, maximum power occurs at about 6000 to 7000 RPM about one and half times the speed of maximum torque.

Torque and power both have functions at the engine speed. At low speeds, torque increases with increasing engine speed. When engine speed increases further, torque reaches its maximum point and then decreases. Torque is reduced because the engine cannot swallow a full charge from the air at a higher speed. The indicator power increases with engine speed, power increases to the maximum point and then decreases at higher speeds. This is because friction losses increase with speed and become a dominant factor at very high speeds. For most car engines, maximum power occurs at around 6000 to 7000 RPM, about one and a half times the speed at maximum torque.

\section{Conclusion}

Based on the results and discussion of the research that has been done, it can be concluded that there is an effect of torque generated in $125 \mathrm{cc}$ motorcycle testing using camshaft racing, at $4500 \mathrm{rpm}$ rotation an increase in torque of $1.21 \mathrm{Nm}(18.42 \%)$, while at $6000 \mathrm{rpm}$ torque increased by $1.61 \mathrm{Nm}(22.61 \%)$ and at engine speed of $7500 \mathrm{rpm}$ the torque generated increased at the use of camshaft racing by $1.7 \mathrm{Nm}(30.20 \%)$.

There is an effect of the power generated in $125 \mathrm{cc}$ motorcycle testing using camshaft racing, at $4500 \mathrm{rpm}$ rotation, there was an increase in power by $0.82 \mathrm{~kW}(26.37 \%)$, whereas at $6000 \mathrm{rpm}$ rotation the power increased by $0.99 \mathrm{~kW}(22.10 \%)$ and at $7500 \mathrm{rpm}$ engine speed the power generated increases in the use of camshaft racing by $1.46 \mathrm{~kW}(33.87 \%)$.

\section{References}

[1] Thomas. G, Simon. D, and Michelini. J.: Biogeography-based optimization of a variable camshaft timing system. Engineering Applications of Artificial Intelligence. 45. pp. 376-387 (2015)

[2] Vaidya. B, Makrakis. D, and Moufta. HT.: Security and Privacy-Preserving Mechanism for Aggregator Based Vehicle-to-Grid Network. EAI Endorsed Transactions on Ambient Systems. pp. 75-85 (2014)

[3] Maksum. H, and Purwanto. W.: Pressure analysis of the ideal intake manifold with the vibration parameters at the diesel engine. Journal of Physics: Conference Series. 1317 (2019)

[4] Bonatesta. F, Altamore. G, Kalsi. J, and Cary. M.: Fuel economy analysis of part-load variable camshaft timing strategies in two modern small-capacity spark ignition engines. Applied Energy. 164. pp. 475-491 (2016) 
[5] Zhao. Y, Zhang. K, and Di, J. Structural Design of Two-Cylinder Single Overhead Camshaft. Materials Science and Engineering. 301 (2018)

[6] Mahendra. S. Analysis Of The Effect Of Camshaft Duration On The Performance Of Honda Tiger 200 Cc Fuel Motor Tune-Up Drag Bike. Journal of Physics: Conference Series. 1273 (2019)

[7] Lin. DY, Hou. BH, and Lan. CC. A balancing cam mechanism for minimizing the torque fluctuation of engine camshafts. Mechanism and Machine Theory. 108. pp. 160-175 (2017)

[8] Purwanto. W, Sugiarto. T, Maksum. H, Putra. DS, and Alwi. E. comparison of three topologies rotor to improve efficiency and torque for high speed spindle motor applications. Applied Information Technology and Innovation. (2018)

[9] Wahyu Hidayat. W. Motor Bensin Modern. Rineka Cipta. Jakarta (2012)

[10] Pulkrabek. W. Engineering Fundamental of the Internal Combustion Engine second edition. Pearson Prentice-Hall. New Jersey (2004)

[11] Maksum. H. Teknologi Motor Bakar. pp. 15. Department of automotive. Universitas Negeri Padang. Padang (2012) 